\title{
THE PENDULAR-FUNICULAR LIQUID TRANSITION AND SNOW METAMORPHISM
}

\author{
By A. Denoth \\ (Institut für Experimentalphysik der Universität Innsbruck, Schöpfstrasse 41, \\ A-6020 Innsbruck, Austria)
}

\begin{abstract}
AвSTRACT. The influence of snow structure on the liquid water distribution is recorded by measuring the highfrequency relative permittivity. The structure is characterized by the size and the shape of the ice grains, which are derived by analyzing the static dielectric constant and by analyzing photographs of the surface of the snow samples. The liquid distribution is very sensitive to the liquid saturation and to the shape of the ice grains; it is unaffected by the grain size. A transition from the pendular into the funicular mode of liquid distribution occurs in the range of 7 to $18 \%$ saturation. This transitional zone is very sensitive to the structure of snow; it decreases from approximately 13 to $18 \%$ liquid saturation for new snow to 7 to $12 \%$ saturation for old, coarse-grained snow.
\end{abstract}

RÉsumé. La transition entre les distributions pendulaires et funiculaires de l'eau liquide dans la neige et les métamorphoses de la neige. L'influence de la structure de la neige sur la distribution de l'eau liquide est décelée par des mesures de permittivité relative aux hautes fréquences. La structure est caractérisée par la dimension et la forme des grains de glace, qui sont déduites de l'analyse de la constante diélectrique statique et de celle de photographies de la surface des échantillons de neige. La distributioin de l'eau liquide est très sensible à l'état de saturation et à la forme des grains de glace; elle n'est pas affectée par la taille des grains. Dans la zone entre 7 et $18 \%$ de saturation, on observe un passage du mode de distribution pendulaire du liquide vers le mode funiculaire. La zone de transition est très sensible à la structure de la neige; elle décroit depuis approximativement 13 à $18 \%$ de saturation liquide pour la neige fraîche jusqu'à 7 à $12 \%$ de saturation pour de la vieille neige à grains grossiers.

Zusammenfassung. Die Metamorphose von Schnee und der Übergang von der "pendular" in die "funicular" Verteilung des freien Wassers. Der Einfluss der Schneestruktur auf die Verteilung des freien Wassers wird durch die Messung der Hf-Dielektrizitätskonstante erfasst. Die Struktur wird dabei durch die Gestalt und die Grösse der Eiskörner charakterisiert. Diese Grössen werden aus Photographien der Oberfläche der Schneeproben gewonnen beziehungsweise auch aus der Analyse der statischen Dielektrizitätskonstante. Die Verteilung des freien Wassers im Schnee hängt im wesentlichen von der Wassersättigung und der Gestalt der Eiskörner ab; die Korngrösse hingegen zeigt keinen Einfluss. Der Übergang von der "pendular" in die "funicular" Verteilung des freien Wassers tritt bei Sättigungen zwischen 7 und $18 \%$ auf, wobei ein erheblicher Struktureinfluss festzustellen ist. Diese Übergangszone tritt bei Neuschnee im Bereich von 13 bis $18 \%$ Sättigung und bei altem, grobkörnigen Schnee im Bereich von 7 bis $12 \%$ Sättigung auf.

\section{LIST OF SYMBOLS AND UNITS}

$d_{\mathrm{m}} \quad$ mean grain-size, $\mathrm{mm}$

$g_{\mathrm{i}} \quad$ shape factor of the ice grains

$g_{1} \quad$ shape factor of the liquid inclusions

$m \quad$ ratio of the principal axis of the ice spheroids

$S \quad$ water saturation (water volume/pore volume)

$S_{\mathrm{c}} \quad$ critical saturation

$S_{\mathrm{i}} \quad$ irreducible saturation

$W \quad$ water content (water volume/total volume)

$\varepsilon \quad$ dielectric constant of snow at an arbitrary frequency

$\varepsilon_{\mathrm{i}} \quad$ dielectric constant of ice at $0^{\circ} \mathrm{C}$

$\varepsilon_{\mathrm{s}} \quad$ static dielectric constant of snow 


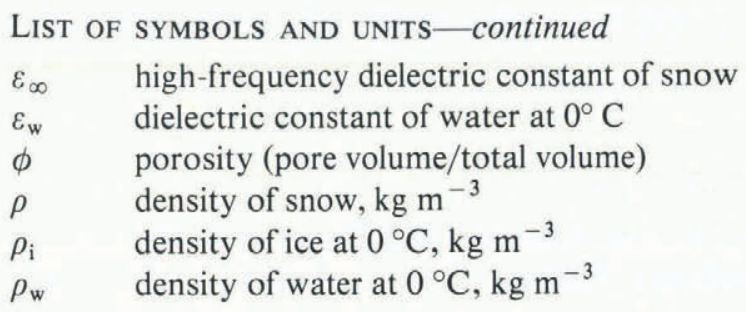

\section{INTRODUCTION}

Most of the important material properties of the porous system snow depend on liquid-water saturation and liquid distribution. As the water content increases, granular porous material typically shows a sudden transition from the pendular into the funicular mode of water distribution. This transition causes rapid changes in the physical properties.

Based on a model of face-centered spherical grains, Colbeck (1973) suggested that the transition occurred at a liquid saturation of about $14 \%$ of the pore volume. From measurements of the dielectric constant of wet snow, a transitional zone in the range of 11 to $15 \%$ liquid saturation was found experimentally (Denoth, 1980). Additional information as to the upper limit of the pendular distribution was derived from measurements of the drainage-flow of free water through aged snow with rounded ice grains (Denoth and others, 1979).

It is obvious that the snow structure, and therefore the stage of snow metamorphism, influences the way free water is distributed around contact points of ice grains. In this paper, results of measurements of the pendular-funicular liquid transition at different stages of snow metamorphism are reported.

\section{SNOW CLASSIFICATION}

In order to account for the influence of snow metamorphism on the pendular-funicular transition, the snow samples have been classified according to the size and the shape of the ice grains or clusters. Assuming that the ice grains can be represented by spheroids, the shape is characterized by the ratio $m$ of the two principal axes $a_{1}$ and $a_{2}$ of the ellipsoids: $m=a_{1} / a_{2}$. The axial ratio $m$ was determined experimentally using two different methods: by analyzing photographs of the surface of the snow samples or by an analysis of the static dielectric constant (Denoth, in press) based on the mixing formula of Polder and van Santen.

Polder and van Santen (1946) developed a general theory to calculate the relative permittivity of a mixture containing ellipsoidal inclusions. In an adapted form for the system of snow, this formula reads as follows:

$$
\varepsilon-1-\varepsilon \frac{1-\phi}{3}\left(\varepsilon_{\mathrm{i}}-1\right) \sum_{j}\left(\varepsilon+\left(\varepsilon_{\mathrm{i}}-\varepsilon\right) g_{\mathrm{i}, j}\right)^{-1}-\varepsilon \frac{W}{3}\left(\varepsilon_{\mathrm{w}}-1\right) \sum_{k}\left(\varepsilon+\left(\varepsilon_{\mathrm{w}}-\varepsilon\right) g_{1, k}\right)^{-1}=0 .
$$

The theory of Polder and van Santen is of particular importance for modelling the dielectric constant of snow, because it allows us to account for the snow structure by the shape factors $g_{\mathrm{i}, j}$ and to account for the structure and distribution of liquid inclusions by the shape factors $g_{1, k}$. Consequently, the stage of snow metamorphism may be taken into account in this theory. The general applicability of this theory to snow has been shown by Denoth and Schittelkopf (1978). 
A detailed analysis and an application to three different types of wet snow were given by Colbeck (1980).

The shape factor $g_{\mathrm{i}, j}$ required in Equation (1) can be calculated from the axial ratio $m$ of the ice grains (Stoner, 1945):

$$
\begin{gathered}
g_{\mathrm{i}, 1}=g_{\mathrm{i}, 2}=\frac{1}{2}\left(1-g_{\mathrm{i}, 3}\right), \\
g_{\mathrm{i}, 3}=\frac{1}{1-m^{2}}\left(1-m\left(1-m^{2}\right)^{-1 / 2} \cos ^{-1} m\right), \quad m<1 .
\end{gathered}
$$

To account for the influence of snow metamorphism on liquid distribution, the snow samples have been grouped into three types according to their shape factor $g_{\mathrm{i}}$ and the mean grain-size $d_{\mathrm{m}}$ : Snow type I is characterized by $d_{\mathrm{m}}<0.5 \mathrm{~mm}$ and $g_{\mathrm{i}} \leqslant 0.06$; this corresponds widely to new snow or to snow which has not undergone appreciable metamorphosis. Snow type II is characterized by $0.5<d_{\mathrm{m}} \leqslant 1 \mathrm{~mm}$ and $0.09 \leqslant g_{\mathrm{i}} \leqslant 0.16$; this corresponds widely to aged, Alpine snow, some days to weeks old. Snow type III is characterized by $d_{\mathrm{m}}>1 \mathrm{~mm}$ and $0.18 \leqslant g_{\mathrm{i}} \leqslant 0.33$; this corresponds to old, coarse-grained snow or firn. A compilation of these characteristic parameters for the classification of snow samples is given in Table I.

\section{EXPERIMENTAL PROCEDURE}

Based on the mixing formula of Polder and van Santen (Equation (1)), the shape factor $g_{1}$ of the liquid inclusions was determined experimentally by measuring the high-frequency relative permittivity $\varepsilon_{\infty}$ of wet snow, liquid saturation, and porosity. The liquid content was measured with a freezing calorimeter; porosity and saturation were calculated from the density $\rho$ and the water content $W$ of the snow sample:

$$
\begin{gathered}
\phi=1-\left(\rho-\rho_{\mathrm{w}} W\right) / \rho_{\mathrm{i}}, \\
S=W / \phi .
\end{gathered}
$$

The shape factor $g_{\mathrm{i}}$ of the ice grains was calculated from the static dielectric constant $\varepsilon_{\mathrm{s}}$ of the snow sample using Equation (1) with the appropriate values for the static dielectric constants of the components. In addition, for some snow samples, $g_{\mathrm{i}}$ was calculated from the photographically determined axial ratio of the ice grains using Equation (2).

In order to determine with high accuracy $\varepsilon_{\mathrm{s}}$ and $\varepsilon_{\infty}$ using Equation (1), it was necessary to measure the relative permittivity in the frequency range of $100 \mathrm{~Hz}$ up to $100 \mathrm{MHz}$. In the frequency range of $100 \mathrm{~Hz}$ up to $20 \mathrm{MHz}$ a capacitance bridge and a twin-T-bridge were used; in the range of $500 \mathrm{kHz}$ up to $100 \mathrm{MHz}$ the relative permittivity was measured with a network

TABLE I. SNOW CLASSIFICATION CHARACTERISTICS

$\begin{array}{ccc}\begin{array}{c}\text { Snow } \\ \text { type }\end{array} & \begin{array}{c}\text { Mean grain size } \\ d_{\mathrm{m}}, \mathrm{mm} \\ \leqslant 0.5\end{array} & \begin{array}{c}\text { Shape factor } \\ g_{\mathrm{i}}\end{array} \\ \text { I } & & \leqslant 0.06 \\ \text { II } & 0.5-1 & 0.09-0.16 \\ \text { III } & >1 & 0.18-0.33\end{array}$

\begin{tabular}{cl}
$\begin{array}{c}\text { Mean shape } \\
\text { factor } \\
g_{\mathrm{i}}\end{array}$ & \multicolumn{1}{c}{ Remarks } \\
$0.031 \pm 0.027$ & new, fine-grained \\
& snow \\
$0.127 \pm 0.030$ & aged snow \\
$0.218 \pm 0.037$ & old, coarse-grained \\
& snow; firn
\end{tabular}


analyser. The limiting relative permittivities $\varepsilon_{\mathrm{s}}$ and $\varepsilon_{\infty}$ were obtained by a least-square-fit using the model of Cole and Cole (1941). The measurements were carried out in natural snow cover in the Stubai Alps at $3000 \mathrm{~m}$ a.s.l. (Schaufelferner/Daunferner).

\section{LIQUID DISTRIBUTION}

For the three different types of snow characterized in Table I, the shape factor $g_{1}$ is shown against liquid saturation in the Figures 1 to 3 . The solid line shown in the figures represents a least-square approximation using Chebyshev polynomials. The weight function was chosen according to the relative importance of the errors of $g_{1}$ in the different regimes of liquid saturation. The error $E\left(g_{1}\right)$ of $g_{1}$ is mainly determined by the errors in measuring liquid saturation and snow porosity. Typically it is $E\left(g_{1}\right)<0.1$ for saturations $S>2 \%$; it increases to about $E\left(g_{1}\right) \approx 0.7$ for lower saturations.

Figure 1 represents type I snow, corresponding to new snow or snow which has not undergone appreciable metamorphosis. At low water saturations $0 \leqslant S \leqslant S_{\mathrm{c}}$ the shape factor $g_{1}$ increases monotonically and takes an approximately constant value of $g_{1} \approx 0.051$ for saturations exceeding a critical saturation $S_{\mathrm{c}} \approx 8 \%$. In the saturation range of $13 \% \leqslant S<18 \%$ a transitional zone between the pendular and the funicular mode of liquid distribution is formed. This transition is characterized by a change in the shape factor from $g_{1} \approx 0.053$ in the pendular regime to $g_{1} \approx 0.091$ in the funicular regime. In the funicular regime, the shape factor $g_{1}$ shows only a small increase with increasing saturation.

Figure 2 represents the shape factor $g_{1}$ for type II snow. At low saturations, the shape factor shows a steep increase with increasing saturation. Compared to type I snow, the critical saturation $S_{\mathrm{c}}$ above which the shape factor takes a nearly constant value of $g_{1} \approx 0.054$, is much lower: $S_{\mathrm{c}} \approx 5 \%$. The transition from the pendular into the funicular regime occurs for this type of

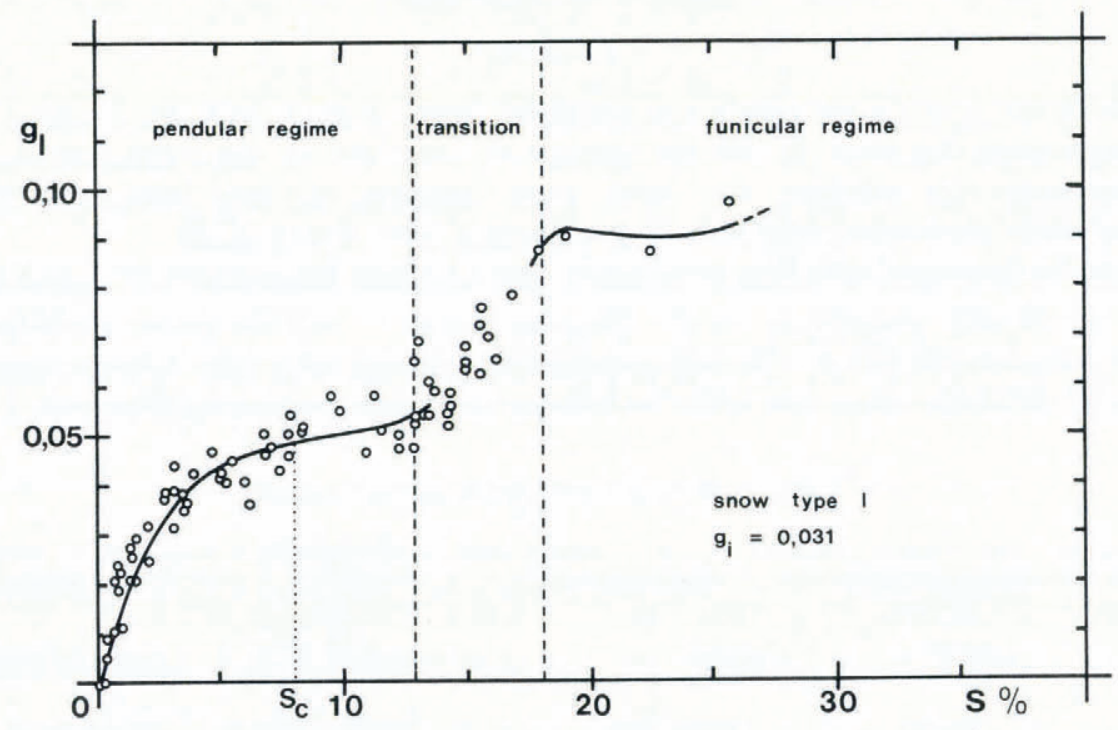

Fig. 1. The shape factor $g_{1}$ for type I snow as a function of water saturation. $S_{\mathrm{c}}$ is the critical saturation: $S_{\mathrm{c}} \approx 8 \%$. The solid line represents a least-square approximation by a fourth-degree polynomial. 


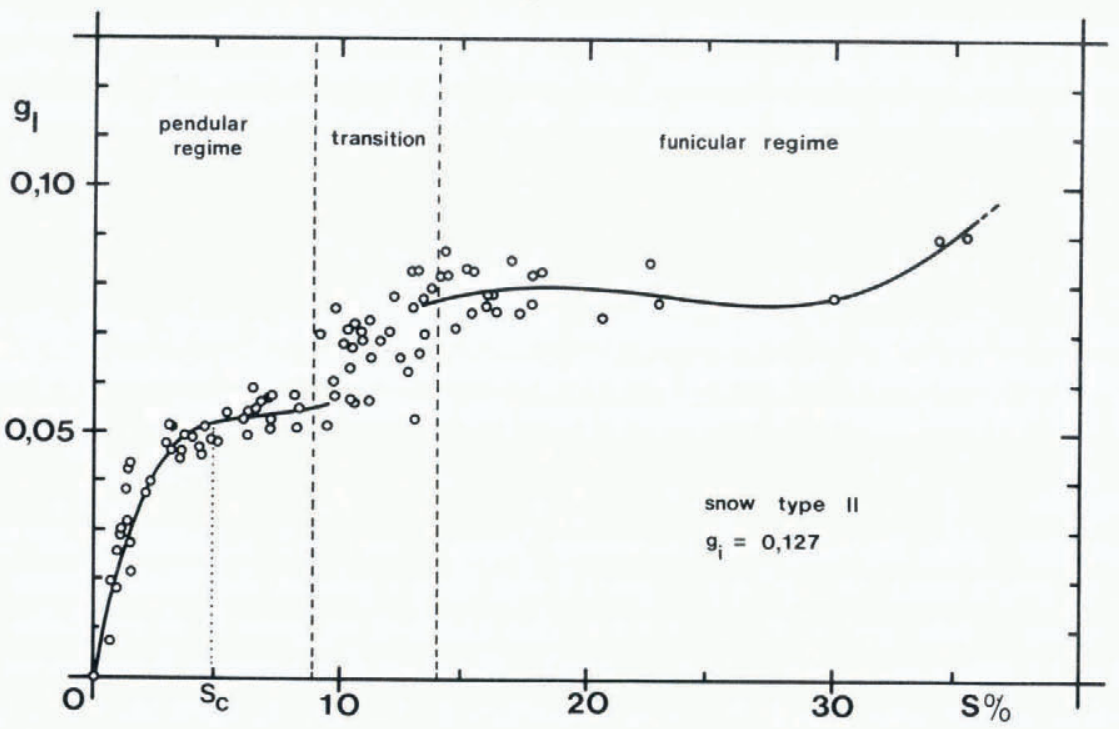

Fig. 2. The shape factor $g_{1}$ for type II snow as a function of water saturation. $S_{\mathrm{c}}$ is the critical saturation: $S_{\mathrm{c}} \approx 5 \%$. The solid line represents a least-square approximation by a fourth-degree polynomial.

snow in the saturation range of $9 \% \leqslant S \leqslant 14 \%$; it is marked by an abrupt change in the shape factor of $g_{1} \approx 0.054$ to $g_{1} \approx 0.080$. A slight increase of $g_{1}$ in the funicular regime with increasing saturation is also observed.

The dependence of $g_{1}$ on water saturation for type III snow is given in Figure 3. The

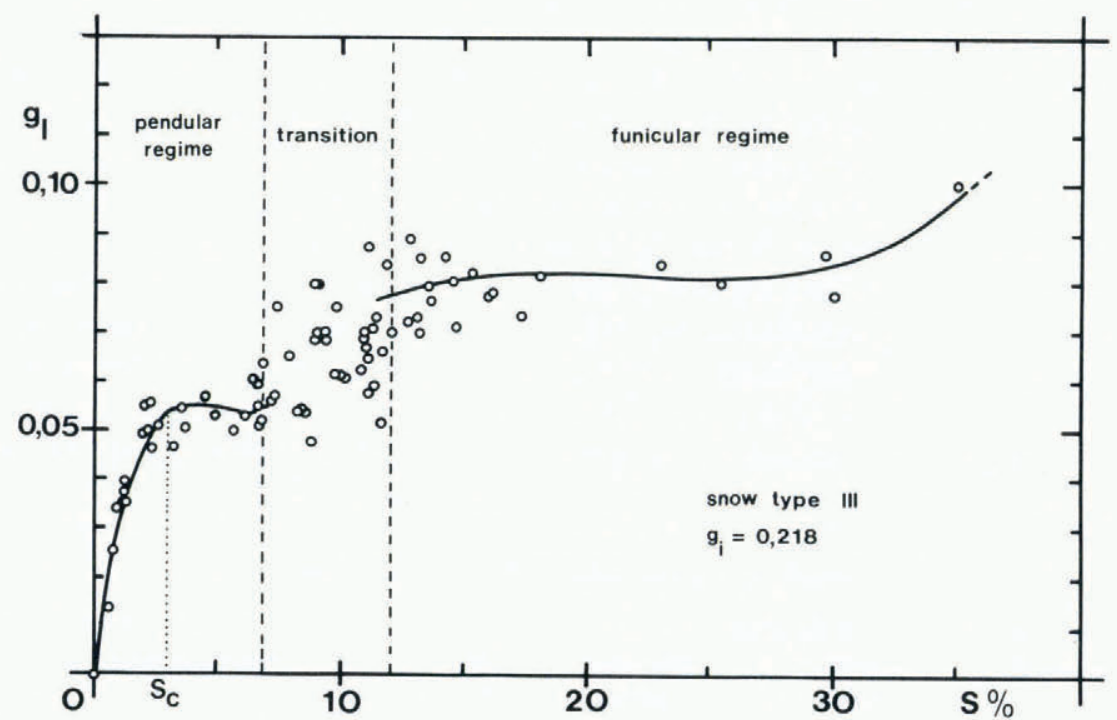

Fig. 3. The shape factor $g_{1}$ for type III snow as a function of water saturation. $S_{\mathrm{c}}$ is the critical saturation: $S_{\mathrm{c}} \approx 3 \%$.

The solid line represents a least-square approximation by a fourth-degree polynomial. 
pendular-funicular transition occurs in the range of $7 \% \leqslant S \leqslant 12 \%$, whereas $g_{1}$ shows a flip-floplike behaviour from $g_{1} \approx 0.054$ to $g_{1} \approx 0.082$. The critical saturation decreases to $S_{\mathrm{c}} \approx 2 \%$ to $3 \%$. In the funicular regime, the shape factor shows also a gradual increase with increasing liquid saturation.

\section{Discussion}

Independent of the stage of metamorphism, liquid water in snow exists generally in four different types of distribution depending on the amount of liquid water present: the pendular regime with two different zones, the transitional zone, and the funicular regime.

\section{Pendular regime}

The pendular stage includes the saturation regime from the adsorbed-liquid limit to saturations at which some of the liquid menisci and fillets coalesce and form a more or less continuous water matrix. The solid-ice matrix is characterized by clusters of ice grains and by the formation of fillets and veins (Colbeck, 1980). Therefore the average shape factor of the water inclusions is very sensitive to the liquid saturation: at very low saturations, $g_{1}$ is controlled by the shape of the water menisci surrounding contact points of ice grains; $g_{1} \approx 0$. Because of the small cross-sectional area of the menisci or fillets, capillary forces may be dominant in this saturation regime. With increasing liquid saturation, the veins become filled with water; $g_{1}$ increases. Since approximately two-thirds of the water is retained in the veins - only one-third in the menisci or fillets - the average shape factor $g_{1}$ is mainly controlled by the shape of the veins: this is the case for saturations exceeding the critical saturation $S_{\mathrm{c}}$. As the cross-sectional area of the veins is much larger than that of the menisci and fillets, gravitational forces may be dominant in the saturation regime $S>S_{\mathrm{c}}$; this is the case for a freely draining seasonal snow cover with a liquid-water content $W$ normally in the range of 3 up to $7 \%$ by volume.

The critical saturation $S_{\mathrm{c}}$ separates therefore two significantly different zones within the pendular regime: a zone with saturations $S<S_{\mathrm{c}}$, characterized by a liquid shape factor which strongly depends on water saturation, and a zone with saturations $S>S_{\mathrm{c}}$, characterized by an approximately constant shape factor $g_{1} \approx 0.053$. At saturations below the critical value $S_{\mathrm{c}}$, capillary forces may be dominant; at saturations exceeding the critical value $S_{\mathrm{c}}$, however, gravity forces may be dominant. It may be of interest in this connection that the irreducible liquid saturation $S_{\mathrm{i}}$ derived from long-term drainage experiments (Denoth and others, 1979; cf. also Colbeck, 1974) compares favourably with the critical saturation discussed here. The irreducible saturation also decreases with wet-snow metamorphism. So, for comparison purposes, $S_{\mathrm{i}}$ is shown in Table II together with the characteristic parameters $g_{\mathrm{i}}, g_{1}, S_{\mathrm{c}}$, and the saturation $S_{\mathrm{t}}$ at the pendular-funicular transition for the three types of snow defined in Table I.

TABLE II. COMPILATION OF THE CHARACTERISTIC SNOW PARAMETERS

\begin{tabular}{|c|c|c|c|c|c|c|}
\hline Snow & Mean shape & Liquid & actor $g_{1}$ & & & Saturation at the \\
\hline type & factor $g_{\mathrm{i}}$ & $\begin{array}{l}\text { pendular } \\
\text { regime }\end{array}$ & $\begin{array}{l}\text { funicular } \\
\text { regime }\end{array}$ & $\begin{array}{l}S_{\mathrm{c}} \\
\%\end{array}$ & $\begin{array}{l}S_{\mathrm{i}} \\
\%\end{array}$ & $\begin{array}{c}\text { pendular-funicular transition } \\
\qquad S_{\mathrm{t}}\end{array}$ \\
\hline I & $0.031 \pm 0.027$ & $\leqslant 0.053$ & $>0.085$ & 8.0 & $7-10$ & 13 to $(18)$ \\
\hline II & $0.127 \pm 0.030$ & $\leqslant 0.055$ & $>0.075$ & 5.0 & $5-7$ & 9 to 14 \\
\hline III & $0.218 \pm 0.037$ & $\leqslant 0.055$ & $>0.080$ & 3.0 & $2-4$ & 7 to 12 \\
\hline
\end{tabular}




\section{Transitional zone}

The transitional zone, which is characterized by a more or less rapid change from the pendular into the funicular mode of liquid distribution, is highly influenced by the stage of snow metamorphism. As the ice grains round off, and therefore the shape factor $g_{i}$ of the solid-ice matrix increases, the transitional zone shifts to lower values of liquid saturation. In addition to that, the gradual transition from the pendular into the funicular regime for type I snow switches into an abrupt, flip-flop-like transition for type III snow. This change in liquid distribution at the transition also changes other physical properties such as, for example, the microwave reflectance and the water flow characteristics.

\section{Funicular regime}

The funicular regime is characterized by a more or less continuous water matrix; the snow grains are completely surrounded by water and the air exists in isolated bubbles trapped between ice grains. Therefore, the clusters of ice grains - a stable configuration in the pendular regime-break down into single, isolated ice grains. Changes in liquid saturation, therefore, cause only small changes in liquid distribution; this can also be concluded from the small changes of the shape factor $g_{1}$.

As the natural snow cover is typically inhomogeneous, the funicular mode of water distribution is usually formed over impermeable boundaries and interfaces. Therefore, the funicular regime is of particular importance, as the comparably high saturation at these points cause rapid snow metamorphism (Colbeck, [1975]) and leads also to the formation of unstable water channels which, in turn, significantly affect the flow field (Colbeck, 1979). Here it must be noted, however, that in the funicular regime electric interactions between various water aggregates and also between ice grains can no longer be neglected. This limits the applicability of the basic theory of Polder and van Santen (cf. Equation (1)) to saturations below approximately $30 \%$.

\section{ACKNOWLEDGEMENT}

The research reported here has been sponsored by the Fonds zur Förderung der wissenschaftlichen Forschung through Project No. 3888. The Wintersport Tirol AG is thanked for supporting the field work in the Stubai Alps.

$M S$. received 24 July 1981

\section{REFERENCES}

Colbeck, S. C. 1973. Theory of metamorphism of wet snow. U.S. Cold Regions Research and Engineering Laboratory. Research Report 313.

Colbeck, S. C. 1974. The capillary effects on water percolation in homogeneous snow. Journal of Glaciology, Vol. 13, No. 67, p. 85-97.

Colbeck, S. C. [1975.] Grain and bond growth in wet snow. [Union Géodésique et Géophysique Internationale. Association Internationale des Sciences Hydrologiques. Commission des Neiges et Glaces.] Symposium. Mécanique de la neige. Actes du colloque de Grindelwald, avril 1974, p. 51-61. (IAHS-AISH Publication No. 114.) 
Colbeck, S. C. 1979. Water flow through heterogeneous snow. Cold Regions Science and Technology, Vol. 1, No. 1, p. $37-45$.

Colbeck, S. C. 1980. Liquid distribution and the dielectric constant of wet snow. NASA Conference Publication 2153, p. 21-39.

Cole, K. S. and Cole, R. H. 1941. Dispersion and absorption in dielectrics. I. Alternating current characteristics. Journal of Chemical Physics, Vol. 9, No. 4, p. 341-51.

Denoth, A. 1980. The pendular-funicular liquid transition in snow. Journal of Glaciology, Vol. 25, No. 91, p. 93-97.

Denoth, A. In press. Snow structure and electrical properties. [Paper presented at International Workshop on the Properties of Snow, Snowbird, Utah, 1981.]

Denoth, A., and Schittelkopf, H. 1978. Mixing formulas for determining the free water content of wet snow from measurements of the dielectric constant. Zeitschrift für Gletscherkunde und Glazialgeologie, Bd. 14, Ht. 1, p. $73-80$.

Denoth, A. and others. 1979. Study of water drainage from columns of snow, by A. Denoth [and 5 others]. U.S. Cold Regions Research and Engineering Laboratory. Report 79-1.

Polder, D., and Santen, J. H. van. 1946. The effective permeability of mixtures of solids. Physica, Vol. 12, No. 5, p. 257-71.

Stoner, E. C. 1945. The demagnetizing factors for ellipsoids. Philosophical Magazine, Seventh Ser., Vol. 36, No. 263, p. 803-21. 